\title{
Nutritional Status, Personal Hygiene and Health Seeking Behavior of the Workers of British American Tobacco Company, Dhaka, Bangladesh
}

\author{
M J Haque', A Awal', M Rahman ${ }^{3}$, J Sazzad $^{4}$ \\ 1. Professor of Community Medicine. Rajshahi Medical College; Rajshahi. \\ 2. Lecturer, Dept. of Public Health; Varendra University. Email: limonawal@gmail.com \\ 3. Food, Physio \& Safety Inspector, J\&Z group Company, Dhaka. \\ 4. Asst. Surgeon, Charghat Health Complex; Rajshahi.
}

\begin{abstract}
This cross sectional study was carried out among the workers of British American Tobacco Company, Dhaka with a view to explore their nutritional status, personal hygiene and health seeking behavior as because they are working on a tobacco processing company. The sample size was 179 which were selected purposively. The study showed that out of 179 respondents $89(49.7 \%)$ were in the age groups of 30-39 years and the mean age of the respondents were $31.99 \pm 6.01$ years. A large number of respondents $(55.9 \%)$ had monthly family income of Taka 10001-20000 and the mean family income was Taka 12776.54 \pm 5230.13 . Maximum respondents $(73.7 \%)$ were Muslim, more than half $(54.2 \%)$ were shift in charge, $39.1 \%$ of the respondents consisted of 4 family members, $43.6 \%$ respondents were accustomed to other type of eating habit and $38.5 \%$ respondents knew that malnutrition was the effect of lack of proper nutrition, $59.8 \%$ of the respondents knew that night blindness was the disease due to malnutrition, most of the respondents $(91.6 \%)$ performed duties to maintain health, majority (62.0\%) respondents used to do nothing to maintain healthcare for their children and $35.9 \%$ visited doctor's single time in a month, $40.2 \%$ of the respondents told regular tooth brushing as type of healthy habits. Majority (64.8\%) respondents used to brush twice a day, majority (50.8\%) respondents used to wash hand after toileting, majority $(62.08 \%)$ respondents used to bath daily, $43.0 \%$ and $31.8 \%$ of the respondents told that dysentery and diarrhea was due to eating without proper hand washing respectively. Majority (53.6\%) respondents informed that they learned about personal hygiene from television, $45.8 \%$ respondents understood that use of safe water in every work as sanitation. Majority (50.84\%) came from nuclear family; most $(84.92 \%)$ had exercise habit and $40.22 \%$ had education level of class VIII. Most (75.42\%) of the respondents had semi pucca houses and majority $(69.83 \%)$ of the respondents used only water as materials for hand washing. This study provided some important information which might help the concerned authority to take appropriate measures to improve the health status of the workers.
\end{abstract}

Key words: Nutritional status, personal hygiene, health seeking behavior, workers, British American Tobacco Company, Bangladesh

Introduction: Health care seeking behavior is one of the important landmarks to uphold the health status of an individual or a community. Simultaneously personal health care practice is also an important issue to keep some common infectious diseases away. Health care seeking behavior is related with social, economic and cultural factors. ${ }^{1}$ The sequence of curative actions that an individual seeks to cure perceived ill health is known as health seeking behavior. ${ }^{2-3}$ 
Healthy practices varies in urban and rural areas, working environment and sometimes traditional believes ${ }^{4}$ Health care seeking behavior first introduced by the family, community and society. ${ }^{5}$ Women are mostly depends on their husbands for maintaining nutrition and personal gyhiene. ${ }^{6-7}$ Health care seeking behavior is associated with different factors like age, sex, marital status, caste, religion, region/state, family size and parity, level of education, occupation of the head of the family, household wealth/poverty, women's autonomy ${ }^{8-13}$, type of illness, number of days of illness ${ }^{12,14,15}$, awareness of and access to services, perceived quality of service, availability of transport, physical distance of the facility, time taken to reach the facility. ${ }^{12,16-19}$

Materials and Methods: The study was cross-sectional and descriptive in design. The target population included all the workers of British American Tobacco Company, Dhaka. Sample size was 179 (Total number of employee were available at that time). All workers were interviewed (face-to-face) using a semi-structured questionnaire. Statistical analysis was carried out using SPSS program version 16.0. Descriptive variables were explained with mean and standard deviation.

Results: Table 1 shows demography among the workers of British American Tobacco Company, Dhaka, Bangladesh. Table 2 shows that nutritional status, personal hygiene practices and related conditions among the workers of British American Tobacco Company, Dhaka, Bangladesh.

Table 1.The factors assessed in all the study were utilized to describe the nutritional status, personal hygiene practices and related conditions among the studied populations $(n=179)$.

\begin{tabular}{|c|c|c|c|c|c|}
\hline & \multicolumn{2}{|c|}{ Respondents } & & \multicolumn{2}{|c|}{ Respondents } \\
\hline & Frequency & Percent & & Frequency & Percent \\
\hline Age group of the & & & No. of Family & & \\
\hline respondents in years: & 22 & 12.3 & members: & 70 & 39.1 \\
\hline$\overline{(20-24) \text { years group }}$ & 44 & 24.6 & 4 persons & 51 & 28.5 \\
\hline$(25-29)$ years group & 89 & 49.7 & 5 persons & 49 & 27.4 \\
\hline (30-39) years group & 24 & 13.4 & 6 persons & 9 & 5.0 \\
\hline More than 40 years & & & 7 persons & & \\
\hline Designation of the & 2 & 1.1 & Monthly & 69 & 38.5 \\
\hline respondents: & 6 & 3.4 & income & 100 & 55.9 \\
\hline$\overline{\text { Manager }}$ & 74 & 41.3 & $\overline{\text { Taka } 10,000 \text { or less }}$ & 10 & 5.6 \\
\hline Asst. manager & 97 & 54.2 & Taka $10,001-20,000$ & & \\
\hline Supervisor & & & More than Taka & & \\
\hline Shift in-charge & 132 & 73.7 & 20,000 & & \\
\hline Religion of & 41 & 22.9 & $\overline{\mathrm{X}} \pm \mathrm{SD}=\mathrm{Tk}$ & & \\
\hline $\begin{array}{l}\text { respondents: } \\
\text { Muslim } \\
\text { Hindu } \\
\text { Christian }\end{array}$ & 6 & 3.4 & $12776.54 \pm 5230.13$ & & \\
\hline
\end{tabular}


According to the age of the participants about 49.7\% participants were between $30-39$ years of age and $13.4 \%$ above 40 years. The mean age of the respondents was $31.99 \pm 6.01$ years. Majority of the respondents (55.9\%) had monthly family income of Taka 10001-20000, $38.5 \%$ had monthly family income of Taka 10000 or less and a few (5.6\%) had monthly family income of Taka more than 20000. The average monthly family income was Tk. $12776.54 \pm 5230.13$. Most of the respondents (73.7\%) were Muslim. A large number of respondents $(54.2 \%)$ were shift in charge, $41.3 \%$ were Supervisor, 3.4\% were assistant manager and a very few (1.1\%) belonged to Manager by occupation. It was found that $39.1 \%$ family constituted 4 family members, followed by $28.5 \%, 26.4 \%$ and $5.0 \%$ constituted family members of 5, 6 and 7 respectively. Among the respondents $22.9 \%$ were vegetarian, $20.1 \%$ used to eat balanced diet and $13.4 \%$ had diet lack of protein. It was found that $38.5 \%$ respondents knew that malnutrition was the effect of not maintaining nutrition, $33.5 \%$ of the respondents knew infection as a result of not maintaining proper nutrition. Majority (59.8\%) knew that night blindness was the disease due to malnutrition; dental pain and anaemia was mentioned by $20.7 \%$ and $10.6 \%$ respondents respectively. It was also found that $8.9 \%$

Table 2 Assessed of nutritional status, personal hygiene practices and related conditions among the studied populations $(\mathrm{n}=179)$.

\begin{tabular}{|c|c|c|c|c|c|}
\hline & \multicolumn{2}{|c|}{ Respondents } & & \multicolumn{2}{|c|}{ Respondents } \\
\hline & $\begin{array}{c}\text { Freq } \\
\text { uenc } \\
\mathbf{y}\end{array}$ & $\begin{array}{c}\text { Perc } \\
\text { ent }\end{array}$ & & Frequency & Percent \\
\hline $\begin{array}{l}\text { Eating habit: } \\
\text { Balance diet } \\
\text { Vegetarian } \\
\text { Diet lack of protein } \\
\text { Others } \\
\text { Knowing effect of not } \\
\text { maintain nutrition: } \\
\text { Malnutrition } \\
\text { Anemia } \\
\text { Marasmus } \\
\text { Infection } \\
\text { Performing duties to } \\
\text { maintain health: } \\
\text { Yes } \\
\text { No } \\
\text { Knowing name of diseases } \\
\text { due to malnutrition: } \\
\text { Night blindness } \\
\text { Anemia } \\
\text { Dental pain }\end{array}$ & $\begin{array}{c}164 \\
15 \\
\\
107 \\
19 \\
37 \\
16\end{array}$ & $\begin{array}{c}91.6 \\
8.4 \\
59.8 \\
10.6 \\
20.7 \\
8.9\end{array}$ & $\begin{array}{l}\text { Diseases affected by } \\
\text { eating without proper } \\
\text { hand washing: } \\
\text { Diarrhea } \\
\text { Dysentery } \\
\text { Helminthiasis } \\
\text { Don'tknow } \\
\text { Frequency of tooth } \\
\text { brushing: } \\
\text { Once a day } \\
\text { Twice a day } \\
\text { 3times a day } \\
\text { Time schedule of } \\
\text { hand washing: } \\
\text { Before eating } \\
\text { Aftertoileting } \\
\text { Before eating \& after toileting } \\
\text { Time schedule of } \\
\text { bathing: } \\
\text { Daily }\end{array}$ & $\begin{array}{l}57 \\
77 \\
32 \\
13\end{array}$ & $\begin{array}{c}31.8 \\
43.0 \\
17.9 \\
7.3\end{array}$ \\
\hline
\end{tabular}




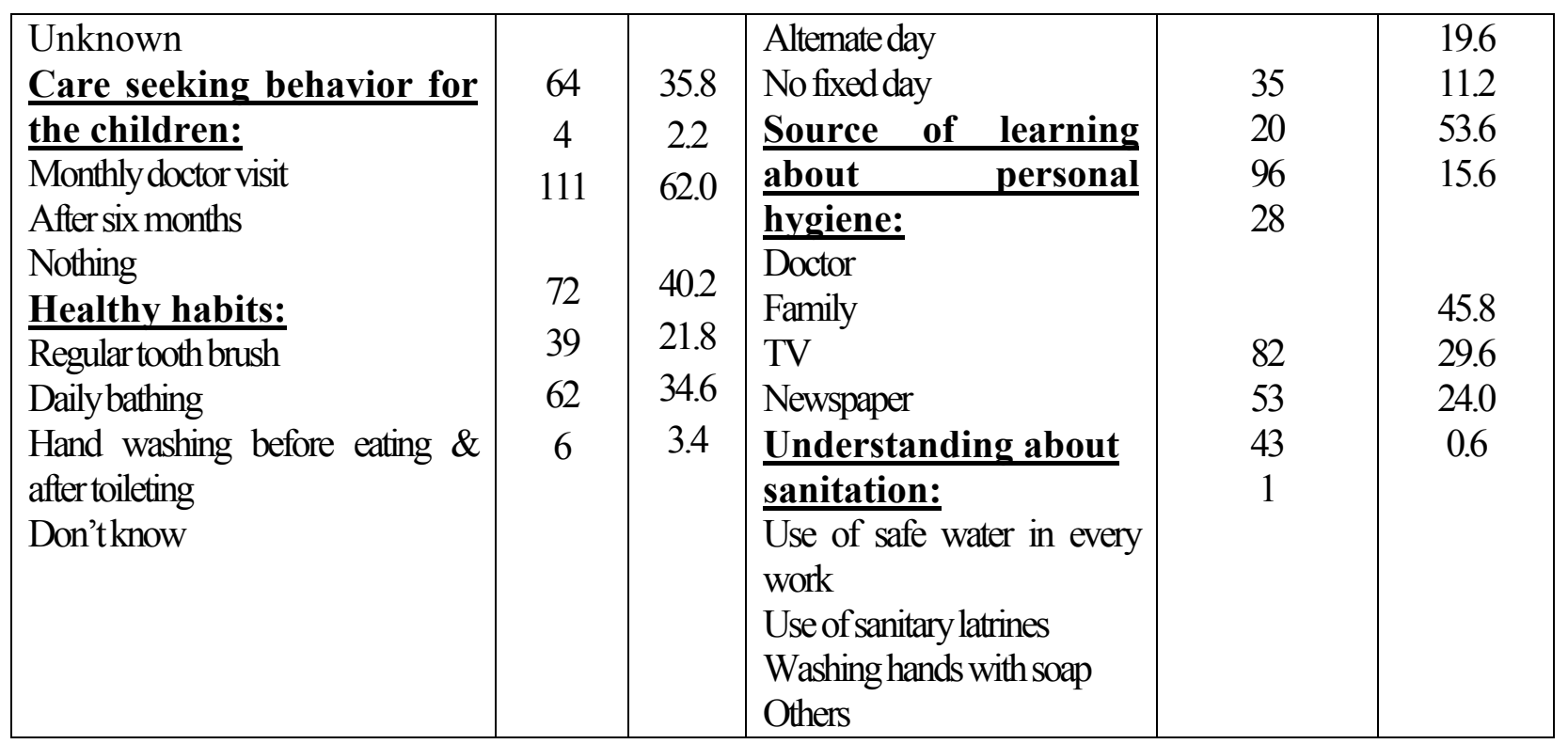

respondents were unknown about the name of diseases due to malnutrition. It was revealed that most $(91.6 \%)$ respondents performed duties to maintain health and only $8.4 \%$ respondents did not perform duties.62.0\% of the respondents did not maintain anything for the proper nutrition of their children. Regarding type of healthy habits it was discovered that $40.2 \%$ of the respondents told regular tooth brushing, followed by hand washing before eating and after toileting and daily bathing constituted $34.6 \%$ and $21.8 \%$ respectively as type of healthy habits. Majority $(64.8 \%)$ respondents used to brush teeth twice a day. It was found that majority (50.8\%) respondents used to wash hands after toileting, followed by $48.0 \%$ who wash hands before eating and toileting. Only a very few (1.1\%) used to wash hands before eating. Majority (62.08\%) respondents used to bath daily, followed by $37.4 \%$ did not bath on fixed day. It was found that $43.0 \%, 31.8 \%$ and $17.9 \%$ of the respondents told that dysentery, diarrhea and Helminthiasis were the diseases due to eating without proper hand washing and only a few $(7.3 \%)$ did not know about the diseases affected by eating without proper hand washing. Majority $(53.6 \%)$ respondents informed that they learned about personal hygiene from television, followed by from doctor. Use of safe water in every work, use of sanitary latrines, washing hands with soap and others were understood about sanitation that comprised $45.8 \%, 29.6 \%, 24.0 \%$ and $0.6 \%$ respectively.

Figure - 1: Distribution of the respondents by type of family.

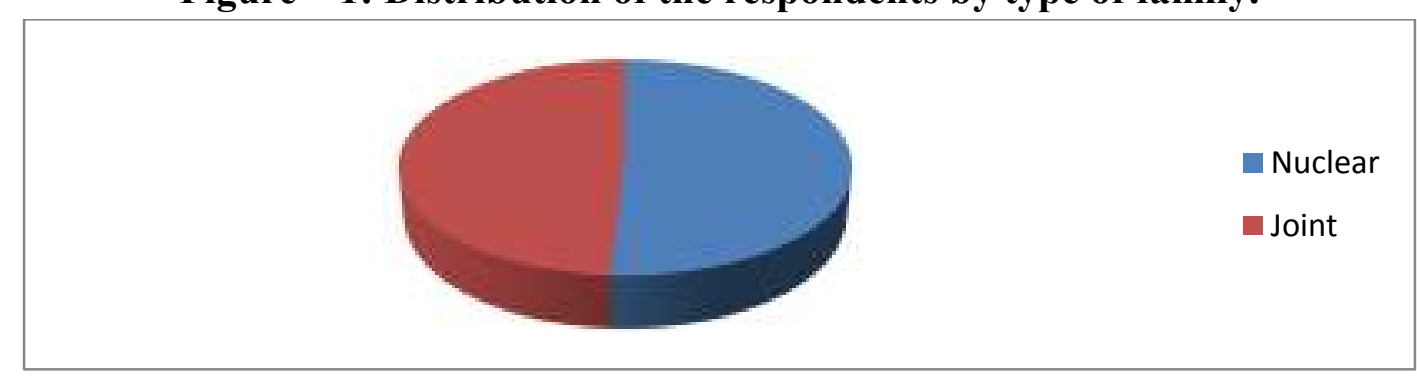


The above figure showed that majority (50.84\%) came from nuclear family and the rest $(49.16 \%)$ belonged to joint family (Fig. no. 01).

Figure - 2: Distribution of the respondents by exercise habit.

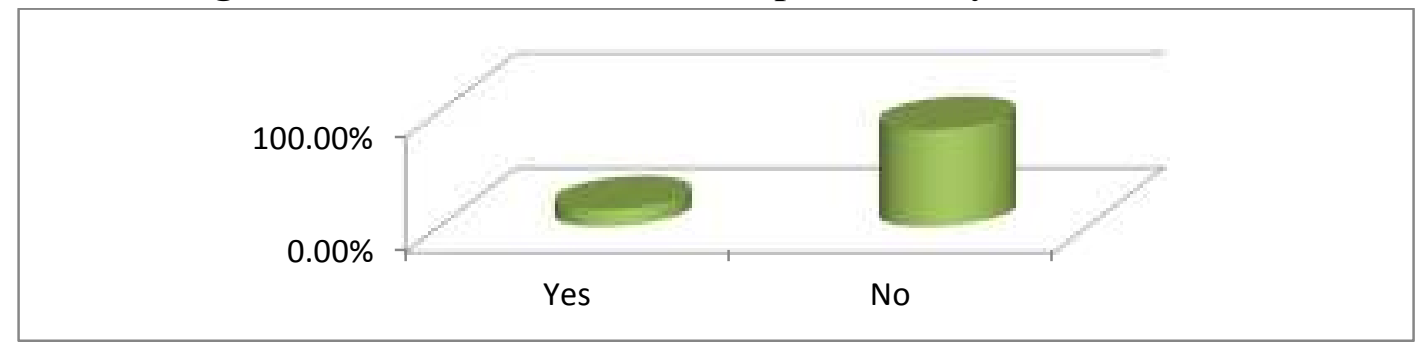

Regarding exercise habit it was found that most (84.92\%) had exercise habit and a few (15.8\%) did not perform exercise (Fig.no.02).

Figure - 3: Distribution of the respondents by educational status.

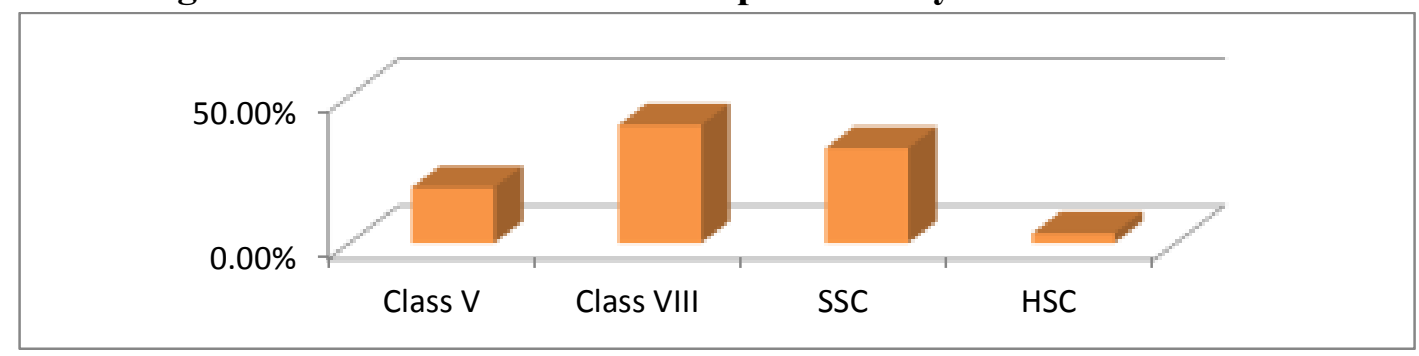

Regarding educational status it was found that out of 179 respondents $40.22 \%$ had education level of class VIII, 32.40\% had SSC, 18.99\% had class V (Fig.no.03).

Figure - 4: Distribution of the respondents by residence.

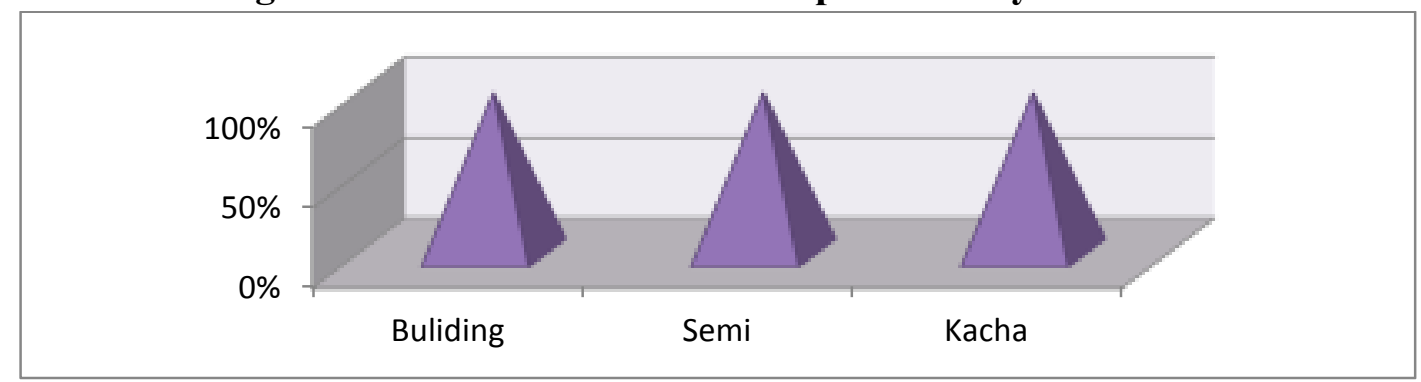

The above figure showed that majority $(75.42 \%)$ of the respondents had semi pucca house, $13.97 \%$ had kancha and the remaining (10.61\%) had building as residence (Fig.no.04). 
Figure - 5: Distribution of the respondents by materials used for hand washing.

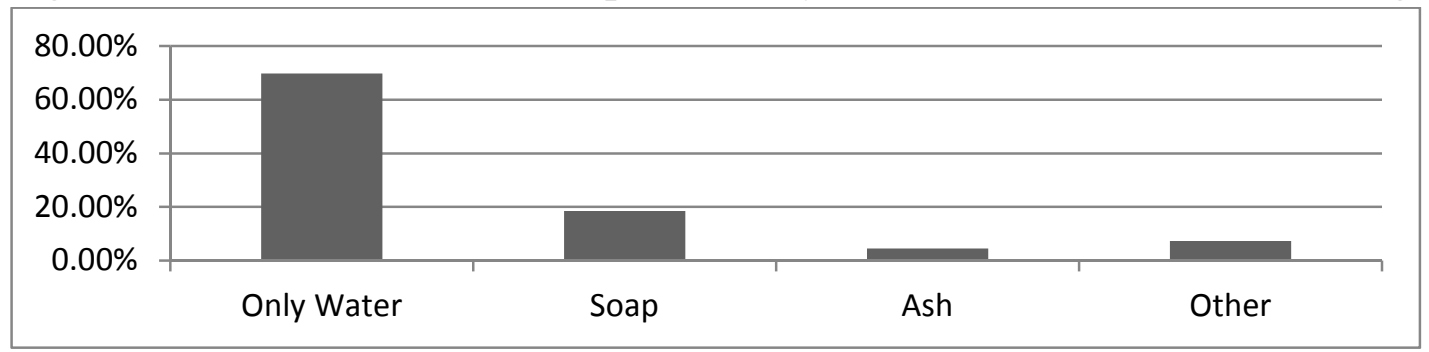

Regarding materials used for hand washing it was revealed that majority $(69.83 \%)$ used only water, followed by soap, other materials and ash by $18.44 \%, 7.26 \%$ and $4.47 \%$ respectively (Fig.no.05).

Discussion: This cross sectional descriptive study was carried out with a view to assess nutritional status, personal hygiene and health seeking behavior of the workers of British American Tobacco Company, Dhaka. The sample size was 179 which were selected purposively. According to the age of the participants about 49.7\% participants were between 30-39 years of age and $13.4 \%$ above 40 years. The mean age of the respondents was $31.99 \pm 6.01$ years. In another study mean age of the respondents were 37.3 years. ${ }^{20}$ Majority of the respondents (55.9\%) had monthly family income of Taka 10001-20000 and the average monthly family income was Tk. $12776.54 \pm 5230.13$. Maximum respondents (73.7\%) were Muslim, followed by Hindu (22.9\%). It was found that out of 179 respondents, majority $(54.2 \%)$ was Shift in charge and $(41.3 \%)$ were Supervisor. It was observed that $(39.1 \%)$ family constituted 4 family members. It was found that (43.6\%) respondents were accustomed to other type of eating habit, followed by vegetarian $(22.9 \%)$. It was observed (38.5\%) respondents knew that malnutrition was the effect of not maintaining nutrition and infection was opined by (26.8\%). Most (59.8\%) of the respondents knew that night blindness was the disease due to malnutrition. Most (91.6\%) respondents performed duties to maintain health. It was revealed that majority $(62.0 \%)$ respondents used to do nothing for their children and (35.9\%) used to visit doctor monthly. It was observed that $(40.2 \%)$ respondents told regular tooth brushing as type of healthy habits followed by hand washing before eating and after toileting constituted (34.6\%). Majority (64.8\%) respondents used to brush teeth twice a day, followed by once a day constituted $(34.6 \%)$. Majority (50.8\%) respondents used to wash hand after toileting, followed by $(48.0 \%)$ used to wash hands before eating and toileting. It was revealed that majority $(62.08 \%)$ respondents used to bath daily, followed by $(37.4 \%)$. It was found that $(43.0 \%),(31.8 \%)$ and $(17.9 \%)$ respondents told that dysentery, diarrhea and Helminthiasis was affected by eating without proper hand washing respectively. Majority (53.6\%) respondents informed that they learned about personal hygiene from TV, followed by from doctor constituted (19.6\%). It was found that use of safe water in every work, use of sanitary latrine and washing hands with soap comprised (45.8\%), $(29.6 \%)$ and $(24.0 \%)$ respectively. Majority (50.84\%) came from nuclear family and the rest $(49.16 \%)$ belonged to joint family. Most $(84.92 \%)$ had exercise habit. It was found that out of 
179 respondents $(40.22 \%)$ had education level of class VIII, (32.40\%) had SSC and (18.99\%) had class V level education. Majority $(75.42 \%$ of the respondents had semi pucca and (13.97\%) had kancha building as residence. Majority (69.83\%) of the respondents used only water as materials for hand washing followed by soap comprised (18.44\%).

Conclusion: Maintaining nutritional status, practicing health care practice with good health seeking behavior makes a man healthy and wealthy. Integrated programs of health promotion in companies should be implemented. The people should be motivated about maintaining personal hygiene and sustain good health habit. Occupational health, safety and healthy working environment should be maintained by the authority.

Author Contribution: First, second, third and fourth author contribute in research 35\%, 30\%, 20\%, 15\% respectively. M J Haque has conceived the idea, conducted literature review, and developed the manuscript. Other authors have drafted the first version of the manuscript. All other authors have meticulously edited the manuscript.

Conflict of Interest: There is no conflict of interest (COI) among the authors in relation profession, financial or any other condition.

\section{References}

1. Price NL, Hawkins KA. Conceptual framework for the social analysis of reproductive health. Journal of Health, Population and Nutrition, 2007; 25(1):24-26.

2. Christman NJ. The health seeking process: An approach to the natural history of illness. Culture, Medicine and Psychiatry, 1980; 1(4): 351-377.

3. Ward H, Mertens T, Thomas C. Health-seeking behavior and the control of sexually transmitted disease. Health Policy and Planning, 1997; 12(1): 19-28.

4. Nyamongo IK. Jealth care switching behavior of malaria patients in a Kenyan rural community. Social Science \& Medicine 2002; 54: 377-386.

5. Delgado E, Sorenson SC, Stuyft P. health seeking behavior and self assessment for common childhood symptoms in rural Guatemala. Annales de IaSociétébelge de medicine tropicale 1994; 74:161-168.

6. Kaona FAD, Siziya S, Mushanga M. The problems of a social survey in epidemiology: an experience from a Zambian rural community. African journal of Medicine and Medical Sciences 1990; 19(3): 219-224.

7. Yamasaki-Nakagawa M, Ozasa K, Yamada N, Osuga K, Shimouchi A, Ishikawa N, et al. Gender difference in delays to diagnosis and health care seeking behavior in a rural area of Nepal. The International Journal of Tuberculosis and Lung Disease, 2001; 5(1): 24-31.

8. Ahmed SM. Exploring health-seeking behavior of disadvantaged populations in rural Bangladesh (PhD Dissertation, No. 05/433). Karolinska University Press, Sweden, 2005.

9. Goldman $\mathrm{N}$, heuveline P. Health seeking behavior for child illness in Guatemala. Tropical Medicine \& International Health, 2000; 5(2): 145-155. 
10. Rani M, Bonu S. Rural Indian women's care-seeking behavior and choice of provider for gynecological symptoms. Studies in Family Planning, 2003; 34(3): 173-185.

11. Thorson A, Hoa NP, Long NH. Health seeking behavior of individuals with a cough of more than 3 weeks. Lancet, 2000; 356: 1823-1824.

12. Tipping G, Segall M. Health care seeking behavior in developing countries: An annotated bibliography and literature review. Development Bibliography 12. Institute of Development Studies, Sussex University. 1995.

13. Yip WC, Wang H, Liu Y. Determinants of choice of medical provider: A case study in rural China. Health Policy and Planning, 1998: 13: 311-322.

14. Islam A, Malik F. Role of traditional birth attendants in improving reproductive health: lessons from the Family Health Project, Sindh. Journal Pakistan Medical Association, 2001; 51(6): 218-222.

15. Sadiq H, Muynck A. Health care seeking behavior of pulmonary tuberculosis patients visiting TB Center Rawalpindi. Journal Pakistan Medical Association, 2001; 51(1): 1016.

16. Fatmi Z, Avan BI. Demographic, socio-economic and environmental determinants of utilization of antenatal care in rural setting of Sindh, Pakistan. Journal Pakistan Medical Association, 2002; 52(4): 138-142.

17. Karim MS. Socio-economic, demographic and health situation in Thatta District. Karachi: Department of Community Health Sciences, Aga Khan University. 1987.

18. Moazam F, Lakhani M. Ethical dilemmas of health care in the developing nations. Journal of Pediatric Surgery, 1990; 25(4): 438-441.

19. Stephenson R, hennink M. Barriers to family planning service use among the urban poor in Pakistan. Asia Pacific Population Journal, 2004; 19(2): 5-26.

20. Ficarra MG, Gualano MR, Capizzi S, Siliquini R, Liguori G, Manzoli L, et al. Tobacco use prevalence, knowledge and attitudes among Italian hospital healthcare professionals. Eur J Public Health. 2011 Feb; 21(1): 29-34. 